Eur J Clin Chem Clin Biochem

1995; 33:569-574

(c) 1995 Walter de Gruyter \& Co.

Berlin - New York

\title{
Autoregulation of Actin Synthesis by Physiological Alterations of the G-Actin Level in Hepatocytes
}

\author{
By Karl H. Reuner ${ }^{1}$, Matthias Wiederhold ${ }^{1}$, Kurt Schlegel ${ }^{1}$, Ingo Just ${ }^{2}$ and Norbert Katz ${ }^{1}$ \\ 1 Institut fïr Klinische Chemie und Pathobiochemie der Universität Giessen, Giessen, Germany \\ 2 Pharmakologisches Institut der Universität des Saarlandes, Homburg/Saar, Germany
}

(Received March 20/March 29, 1995)

Summary: Hypotonic treatment of cultured rat hepatocytes significantly decreased the monomeric G-actin level by $18 \%$ after $120 \mathrm{~min}$ while the level of filamentous F-actin remained essentially unchanged. Simultaneously the level of cellular actin mRNA was increased by $53 \%$.

Incubation of hepatocytes for $120 \mathrm{~min}$ with the F-actin stabilizing toxin phalloidin from Amanita phalloides led to a decrease of G-actin by $70 \%$ and an increase of F-actin by 55\%. Although the toxin dependent decrease of Gactin was much more pronounced than the decrease after hypotonic treatment, the increase of actin mRNA was similar under both conditions. Simultaneous treatment with hypotonic medium did not result in a further decrease of the G-actin level. On the other hand, the G-actin elevating C2 toxin from Clostridium botulinum completely blocked the effects of osmotic stress on G-actin and actin-mRNA content.

The results demonstrate that already an essentially physiological decrease of G-actin without alterations of $F$-actin results in a substancial enhancement of the actin mRNA level, indicating the physiological significance of this autoregulation.

\section{Introduction}

Actin is a main component of the cytoskeletal framework in non-muscle cells. Moreover, it is involved in a variety of intracellular motile processes. Most of the functions of actin depend on the polymerization of monomeric G-actin ${ }^{1}$ ) and depolymerization of filamentous F-actin ${ }^{1}$ ), respectively. This dynamic process is controlled by a number of actin binding proteins $(1-3)$.

The synthesis of actin, similar to other-cytoskeletal proteins, appears to be under autoregulatory control on the basis of the equilibrium between the monomeric and the polymeric form (4-8). Under experimental conditions,

\footnotetext{
1) Abbreviations:

G-actin, globular actin; F-actin, filamentous actin; DNase I, deoxyribonuclease I; S.E. M., standard error of the mean; FITC, fluorescein isothiocyanate; SDS, sodium dodecylsulphate; EGTA, ethylene glycol bis( $\beta$-amino ethyl ether) tetraacetic acid; $k b=10^{3}$ bases.
}

the equilibrium between G- and F-actin can be shifted to the monomeric or to the polymeric form by biological toxins, which arrest actin in one of the two forms. Phalloidin from Amanita phalloides, which is rapidly taken up by hepatocytes in culture, binds to F-actin and dramatically reduces actin depolymerization, resulting in a decreased pool of monomeric G-actin (9). On the other hand, $\mathrm{C} 2$ toxin from Clostridium botulinum specifically ADP-ribosylates non-muscle G-actin in cell free systems (10) as well as in intact cells (11). ADP-ribosylated Gactin acts as a F-actin capping protein (12), thereby increasing the cellular pool of monomeric G-actin (13).

In cultured rat hepatocytes, the stabilizing of F-actin by phalloidin is followed by an increase of actin mRNA, whereas the increase of $\mathrm{G}$-actin by $\mathrm{C} 2$ toxin is followed by a decrease of actin mRNA, indicating an autoregulatory control of actin synthesis (14). However, the metabolic significance of this regulation is unclear, since the 
toxin dependent shifts of G- and F-actin are largely unphysiological. Moreover, a direct effect of the toxins on the actin mRNA level could not be excluded so far.

More physiological shifts of the G-/F-actin equilibrium are observed during hypotonic treatment of hepatocytes, followed by modulation of actin synthesis (15). In the present study, the effect of hypotonic treatment on actin synthesis was compared to the toxin-dependent regulation of actin synthesis. Phalloidin and hypotonic treatment, respectively, led to similar enhancements of actin mRNA although the decrease of G-actin was fourfold stronger in the presence of phalloidin. The effects of hypotonic stress plus phalloidin treatment were not additive. On the other hand, $\mathrm{C} 2$ toxin completely blocked the effects of osmotic stress on G-actin and actin mRNA content. It is concluded that the maximal effects on actin synthesis are already achieved by essentially physiological alterations of the G-actin level.

\section{Materials and Methods}

\section{Materials}

Skeletal $\alpha$-actin (rabbit), DNA, DNase $\mathrm{I}^{2}$ ), phalloidin and rhodamine-labelled phalloidin were obtained from Sigma (Munich, Germany). Medium 199 was supplied by Gibco (Karlsruhe, Germany), collagenase was from Boehringer Mannheim (Germany). Hybond $C$ hybridization membrane and $\left[\alpha-{ }^{32} \mathrm{P}\right] \mathrm{dCTP}$ were purchased from Amersham Buchler (Braunschweig, Germany). All other chemicals were analytical grade and obtained from commercial sources.

\section{Cell culture and osmotic stress}

Hepatocytes were isolated from Wistar rats by collagenase perfusion. Before experimental use, the cells were maintained on $6 \mathrm{~cm}$ Falcon ${ }^{\circledR}$ culture dishes for 18 hours in medium 199 (280 mosmol/l) as described (16). Later on, hypotonic treatment was performed in medium 199 adjusted to $220 \mathrm{mosmol} / \mathrm{l}$ by dilution. For normotonic treatment, this medium was adjusted by addition of sodium chloride to $280 \mathrm{mosmol} / \mathrm{l}$.

\section{Toxins}

The two components I and II of C2 toxin were prepared and activated essentially as described (17). The final toxin concentration was $100 \mu \mathrm{g} / \mathrm{l}$ culture medium of component $\mathrm{I}$ and $200 \mu \mathrm{g} / \mathrm{l}$ of component II. Phalloidin was dissolved in $\mathrm{H}_{2} \mathrm{O}$ and used in a final concentration of $2.5 \mathrm{mg} / \mathrm{l}$.

Measurement of cellular G-actin, F-actin and of protein

The amount of cellular G-actin was determined by DNase I inhibition assay (18), essentially as described (13). Cells pretreated with or without osmotic stress or with toxin, respectively, were lysed by $500 \mu \mathrm{l}$ of freshly prepared, ice-cold lysis buffer containing

\section{2) Enzymes:}

Alanine aminotransferase (EC 2.6.1.2); aspartate aminotransferase (EC 2.6.1.1); deoxyribonuclease I (EC 3.1.4.5); lactate dehydrogenase (EC 1.1.1.27)
$5 \mathrm{mmol} / \mathrm{l}$ potassium phosphate, $\mathrm{pH} 7.6,150 \mathrm{mmol} / \mathrm{l} \mathrm{NaCl}, 2 \mathrm{mmol} / \mathrm{l}$ $\mathrm{MgCl}_{2}, 0.1 \mathrm{mmol} / \mathrm{l}$ dithiothreitol, $0.5 \mathrm{mmol} / \mathrm{ATP}, 0.01 \mathrm{mmol} / \mathrm{l}$ phenylmethylsulphonyl fluoride, $2 \mathrm{mmol} / 1$ EGTA, $5 \mathrm{~g} / 1$ Triton $\mathrm{X}$ 100 and $150 \mathrm{~g} / \mathrm{l}$ glycerol. Cell lysates were scraped off, transferred to Eppendorf test tubes, mixed, placed on ice for $15 \mathrm{~min}$, and homogenized using a syringe. Thereafter, the homogenates were spun for $45 \mathrm{~min}$ at $100000 \mathrm{~g}$ and $4^{\circ} \mathrm{C}$. Small amounts $(10-50 \mu \mathrm{l})$ of supernatants were mixed with $20 \mu \mathrm{l}$ of DNase I solution $(0.1 \mathrm{~g} / \mathrm{l}$ in $50 \mathrm{mmol} / 1$ Tris- $\mathrm{HCl}, \mathrm{pH} 7.5,0.2 \mathrm{mmol} / \mathrm{l}_{\mathrm{r}} \mathrm{CaCl}_{2}$ and $0.01 \mathrm{mmol} / 1$ phenylmethylsulphonyl fluoride). For determination of DNase activity inhibition, $1 \mathrm{ml}$ of prewarmed $\left(25^{\circ} \mathrm{C}\right)$ calf thymus DNA (40 $\mathrm{mg} / \mathrm{l}$ in $100 \mathrm{mmol} / \mathrm{l}$ Tris- $\mathrm{HCl}, \mathrm{pH} 7.5,4 \mathrm{mmol} / 1 \mathrm{MgSO}_{4}, 1.8 \mathrm{mmol} / \mathrm{l}$ $\mathrm{CaCl}_{2}$ ) was added, mixed for $3 \mathrm{~s}$ and immediately transferred into a cuvette for measuring the absorbance at $260 \mathrm{~nm}$ for $40 \mathrm{~s}$ after a total delay of $10 \mathrm{~s}$. Increase of absorbance was measured with a photometer from Pharmacia, and plottet using the Pharmacia-enzyme-kinetik software. The slope of the linear part of the increase in absorbance is directly proportional to the amount of not inhibited DNase added (18). A standard curve for $30-70 \%$ inhibition was obtained by measuring the absorbance after addition of defined amounts of rabbit skeletal muscle G-actin to the reaction mixture instead of cell lysates. G-actin of hepatocytes was referred to cytosolic protein in the $100000 \mathrm{~g}$ supernatants, determined according to Bradford (21), using bovine $\gamma$-globulin as standard. Data were expressed as $\mu \mathrm{g} \mathrm{G}$-actin per $\mathrm{mg}$ cytosolic protein.

F-actin content was measured by binding of rhodamine-labelled phalloidin to actin filaments (19) in permeabilized and formaldehyde fixed hepatocytes with some modifications (20). Cells were maintained on $6 \mathrm{~cm}$ Falcon ${ }^{\circledR}$ culture dishes, washed twice with stabilization buffer $\left(75 \mathrm{mmol} / \mathrm{l} \mathrm{KCl}, 3 \mathrm{mmol} / / \mathrm{MgSO}_{4}, 1 \mathrm{mmol} / \mathrm{l}\right.$ EGTA, $0.2 \mathrm{mmol} / \mathrm{l}$ dithiothreitol, $0.1 \mathrm{mmol} / /$ phenylmethylsulphonyl fluoride, $10 \mathrm{mmol} / 1$ imidazole, $10 \mathrm{mg} / \mathrm{l}$ aprotinin, $\mathrm{pH} 7.2$ ) and permeabilized with $0.3 \mathrm{~g} / 1$ saponin in stabilization buffer for 10 min at room temperature. Cell monolayers were fixed in freshly prepared $30 \mathrm{~g} / \mathrm{l}$ formaldehyde in stabilization buffer for $20 \mathrm{~min}$ at room temperature, washed twice and stained in the dark with 175 $\mu \mathrm{g} / \mathrm{l}$ rhodamine-phalloidin in stabilization buffer for $30 \mathrm{~min}$. After washing thrice with stabilization buffer, extraction of rhodamine-labelled phalloidin was initiated by addition of ice cold HPLC-grade methanol for $30 \mathrm{~min}$ at $-20^{\circ} \mathrm{C}$. Thereafter, the cells were scraped off with a rubber policeman and extraction was continued overnight at $-20^{\circ} \mathrm{C}$. The suspension was centrifuged for $10 \mathrm{~min}$ at $10000 \mathrm{~g}$. Rhodamine in the supernatants was determined by means of a rhodamine-labelled phalloidin standard curve using an Aminco-Bowman spectrophotofluorometer (Colora, Lorch, Germany). Excitation and emission wavelengths were 542 and $563 \mathrm{~nm}$. Cellular protein was determined according to Bradford (21) in parallely cultured hepatocytes lysed in the presence of $5 \mathrm{~g} / \mathrm{l}$ Triton X-100. Data were expressed as ng rhodamine-phalloidin per mg cellular protein.

In addition, the ratio of filamentous to non-filamentous actin was determined by separation of proteins insoluble or soluble in Triton X-100, respectively (22). After treatment of hepatocytes with or without osmotic stress or with toxins, respectively, the cells were lysed by addition of an ice cold Triton solution containing $20 \mathrm{~g} / 1$ Triton X-100, $160 \mathrm{mmol} / 1 \mathrm{KCl}, 20 \mathrm{mmol} / \mathrm{l}$ EGTA, $8 \mathrm{mmol} / \mathrm{l}$ sodium azide, and $40 \mathrm{mmol} / \mathrm{l}$ imidazole $\mathrm{HCl}, \mathrm{pH}$ 7.0. The resulting lysates of hepatocytes were scraped off, transferred to test tubes, vortexed and placed on ice for $15 \mathrm{~min}$. Thereafter, the tubes were centrifuged for $15 \mathrm{~min}$ at $3000 \mathrm{~g}$. The resulting pellets, containing cytoskeletal proteins, were washed once with the Triton solution and dissolved essentially as described (11) in a solution containing $50 \mathrm{~g} / \mathrm{l} \mathrm{SDS}, 50 \mathrm{~g} / 1$ saccharose, $50 \mathrm{~g} / \mathrm{l}$ glycerol, $200 \mathrm{mmol} / \mathrm{l}$ dithiothreitol, and $50 \mathrm{mmol} / 1 \mathrm{Tris}-\mathrm{HCl}, \mathrm{pH} 7.5$. The cytosolic proteins of supernatants were precipitated as described (11) and dissolved as described for cytoskeletal pellet proteins. Both pellet- and supernatant-proteins were analyzed by SDS gel electrophoresis. Filamentous cytoskeletal and non-filamentous cytosolic actin were identified by their relative molecular mass. Quantification was performed by scanning the $M_{\mathrm{r}} 43000$ protein actin using an Epson GT 6000 scanner and the Gel-Image programme from Pharmacia (Freiburg, Germany). 
Detection and quantitation of actin and albumin mRNA

RNA of rat hepatocytes was isolated according to Chomczynski \& Sacchi (23). Northern- and dot blot hybridization was performed as described previously (14). In brief, total RNA (10 $\mu \mathrm{g})$ was subjected to electrophoresis on agarose gel and transferred to a nitrocellulose filter, or was directly dotted onto nitrocellulose, respectively. Hybridization was performed at $42{ }^{\circ} \mathrm{C}$ in a mixture containing formamide $(500 \mathrm{~g} / \mathrm{l})$ using ${ }^{32} \mathrm{P}$-labelled random primed $\mathrm{cDNA}$. As probes were used a $1.3 \mathrm{~kb}$ Pst I fragment of mouse $\beta$-actin cDNA and a $0.8 \mathrm{~kb}$ Pst I fragment of rat albumin cDNA, both cloned into standard bluescript vector (Stratagene, La Jolla, USA). The filters were washed once in SSPE-buffer $(150 \mathrm{mmol} / 1 \mathrm{NaCl}$, $1 \mathrm{mmol} / \mathrm{l}$ EDTA and $10 \mathrm{mmol} / \mathrm{l}$ sodium phosphate, $\mathrm{pH}$ 7.4) containing SDS $(1 \mathrm{~g} / 1)$ at room temperature followed by washing three times in 1:10 diluted SSPE containing SDS (1 g/l) each for 20 $\min$ at $60^{\circ} \mathrm{C}$. The filters were subjected to autoradiography for $12-24 \mathrm{~h}$ and the hybridization signals were quantified by counting in a liquid scintillation counter or by scanning densitometry. The $\beta$-actin mRNA levels were normalized to the levels of albumin mRNA, which were essentially unchanged.

\section{Statistics}

Statistical analysis was performed using Student's t-test.

\section{Measurement of cellular enzyme activities}

The enzymes alanine aminotransferase ${ }^{2}$, aspartate aminotransfer$a^{2} e^{2}$ ) and lactate dehydrogenase ${ }^{2}$ ) were measured in culture medium according to the recommendations of the German Society for Clinical Chemistry (24), using reagents from Boehringer (Mannheim, Germany).

\section{Results}

Influence of osmotic stress on cellular G-actin/F-actin and on actin mRNA

Rat hepatocytes were cultured for 18 hours as described in Materials and Methods. Thereafter the medium 199 was replaced by hypotonic ( $220 \mathrm{mosmol} / \mathrm{l})$ or normotonic (280 mosmol/l) media for $120 \mathrm{~min}$, respectively. Under hypotonic conditions the amount of cytosolic Gactin was significantly decreased by $18 \%$ after $60 \mathrm{~min}$ without further alteration during the next $60 \mathrm{~min}$, indicating that the cells adapted to the hypotonic condition (fig. 1). The decrease of monomeric G-actin was not accompanied by a substantial alteration in the cellular F-actin content as measured by histochemical staining of F-actin using thodamine-labelled phalloidin (tab. 1) as well as by direct quantification of filamentous and non-filamentous actin separated by Triton X-100 extraction and gel electrophoresis (not shown). Reciprocally to the decreased amounts of cytosolic G-actin the cellular level of actin mRNA was enhanced by $53 \%$ after 120 min of incubation with hypotonic medium (fig. 1). The effect of osmotic stress on actin mRNA was specific, since albumin mRNA for control was essentially unchanged as demonstrated by Northern blot analysis (fig. 2).

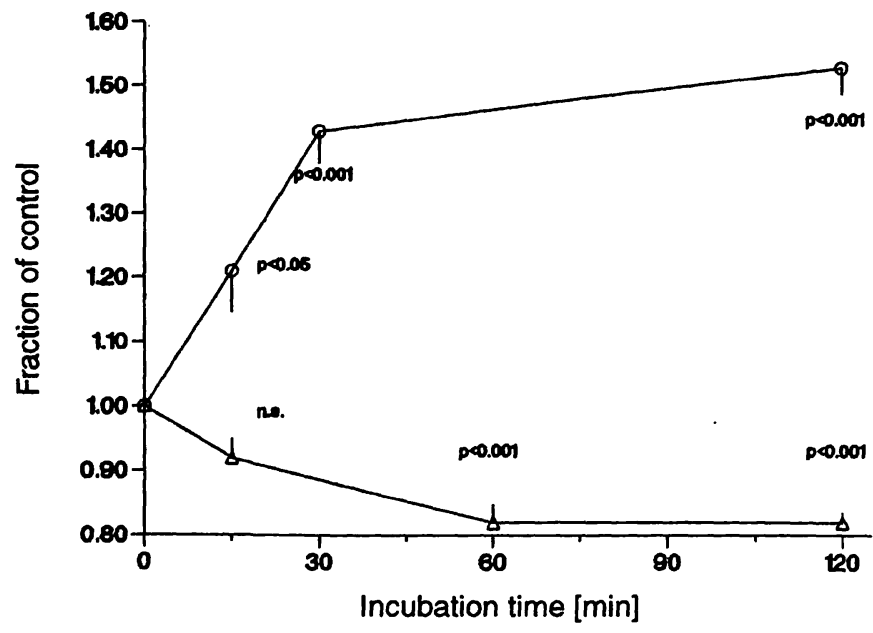

Fig. 1 Influence of osmotic stress on G-actin and on actin mRNA levels in cultured rat hepatocytes.

After culture for 18 hours the normotonic medium was removed and normotonic or hypotonic media were added up to $120 \mathrm{~min}$. Thereafter, monomeric G-actin $(\Delta)$ and actin mRNA $(O)$ were determined as described in Materials and Methods. The initial concentration of G-actin, as measured by DNase inhibition, was $13 \mu \mathrm{g}$ per $\mathrm{mg}$ of cytosolic protein, which was determined as protein soluble in Triton X-100 in the $100000 \mathrm{~g}$ supernatants of hepatocytes. Specific mRNA was measured by Northern- or dot-blot hybridizations using specific $\beta$-actin- and albumin-probes. Actin mRNA levels were normalized to the levels of albumin mRNA, which were essentially unchanged. Data presented are means \pm S.E. M. of 6 separate determinations. The P values were obtained by Student's t-test for unpaired data in comparison with control cells under normotonic conditions $(280 \mathrm{mosmol} / \mathrm{l})$. n. s., not significant.

\section{Modulation of osmotic effects by $\mathrm{C} 2$ toxin and phalloidin}

After primary culture for $18 \mathrm{~h}$, hepatocytes were incubated with normotonic or hypotonic medium with or without phalloidin or C2 toxin, respectively. Under normotonic conditions, phalloidin dramatically decreased cellular G-actin by $70 \%$ after incubation for $120 \mathrm{~min}$, which largely exceeded the decrease by hypotonic treatment (fig. 3a). Simultaneously, the level of F-actin was increased by $55 \%$ (tab. 1). Hypotonic incubation during phalloidin treatment did not result in an additional decrease of G-actin (fig. 3a). On the other hand, treatment with $\mathrm{C} 2$ toxin increased $\mathrm{G}$-actin by about $50 \%$ (fig. 3a) and decreased the F-actin content by $45 \%$ within $120 \mathrm{~min}$ (tab. 1). This effect was identical under normotonic as well as under hypotonic conditions (fig. 3a), indicating that $\mathrm{C} 2$ toxin overcomes the decrease of cellular G-actin by osmotic stress.

The dramatic decrease of G-actin in the presence of phalloidin resulted in an increase of actin mRNA by $39 \%$, which was even less pronounced than the increase of actin mRNA during the moderate decrease of G-actin observed under hypotonic conditions (fig. 3b). This indicates that a physiological decrease of G-actin might be sufficient for a maximal up regulation of actin mRNA. On the other hand, the increase of actin mRNA under 
Tab. I Influence of osmotic stress and of toxin treatment on filamentous F-actin in cultured rat hepatocytes.

Trcatment of cells with osmotic stress was performed as described in Materials and Methods. Incubation with C2 toxin $(100 \mu \mathrm{g} / \mathrm{lcom}-$ ponent $I$ and $200 \mu \mathrm{g} / \mathrm{l}$ component II) or with phalloidin $(2.5 \mathrm{mg} / \mathrm{l})$ was performed under normotonic conditions. F-actin was determined by quantitative binding of rhodamine-labelled phalloidin to actin filaments. After preincubation with unlabelled phalloidin, which disturbs quantitative binding of rhodamine-labelled phalloidin by competition, F-actin was measured by Triton X-100 extraction as described in Materials and Methods. Data are means \pm S.E.M. of 9 single determinations. No significant differences compared to normotonic controls were detected, except after treatment of hepatocytes with $C 2$ toxin or with phalloidin $(p<0.001)$. n. m., not measured.

\begin{tabular}{lllll}
\hline Incubation time & F-actin levels & & & \\
\cline { 2 - 5 } & Normotonic & Hypotonic & C2 toxin & Phalloidin \\
\hline $15 \mathrm{~min}$ & $100 \pm 1.8 \%$ & $103 \pm 2.8 \%$ & n.m. & n.m. \\
$30 \mathrm{~min}$ & $100 \pm 3.8 \%$ & $99 \pm 5.6 \%$ & n.m. & n.m. \\
$60 \mathrm{~min}$ & $100 \pm 2.8 \%$ & $109 \pm 2.5 \%$ & $66 \pm 1 \%$ & n.m. \\
$120 \mathrm{~min}$ & $100 \pm 3.8 \%$ & $98 \pm 2.4 \%$ & $55 \pm 2.8 \%$ & $155 \pm 3 \%$ \\
\hline
\end{tabular}

hypotonic stress was completely abolished by incubation with $\mathrm{C} 2$ toxin, which decreased actin mRNA under normotonic condition by about $20 \%$ (fig. 3 b).

\section{Effects on the hepatocellular integrity}

Hypotonic treatment of hepatocytes did not result in a remarkable release of the cellular enzyme activities, e. g. alanine aminotransferase, aspartate aminotransferase and lactate dehydrogenase, respectively. Also incubation with $\mathrm{C} 2$ toxin or with phalloidin under normotonic conditions did not enhance enzymes in the culture medium compared to the control. Exclusively simultaneous treatment with $\mathrm{C} 2$ toxin or phalloidin as well as with hypotonic medium led to a slight increase of alanine aminotransferase and aspartate aminotransferase activities to 125 to $140 \%$ of control cultures, indicating a moderate injury of hepatocytes.

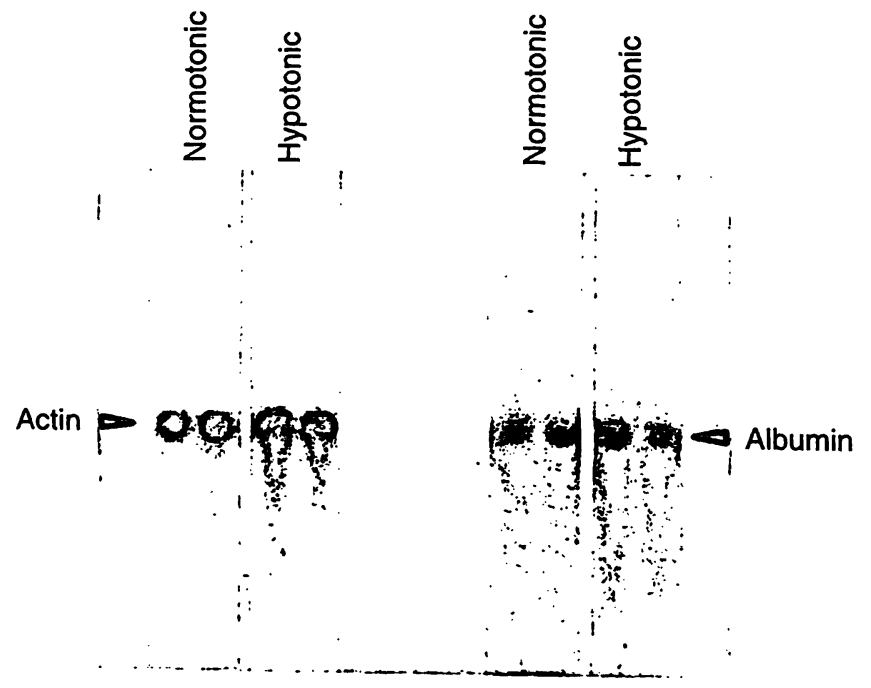

Fig. 2 Northern blot analysis of actin mRNA and albumin mRNA from cultured rat hepatocytes

Cells were treated with normotonic $(280 \mathrm{mosmol} / \mathrm{l})$ or hypotonic ( $220 \mathrm{mosmol} / \mathrm{l})$ medium for $2 \mathrm{~h}$, respectively. Thereafter, RNA was prepared, and Northern blot hybridization was performed as described in Materials and Methods. The autoradiography of a typical experiment is shown.

\section{Discussion}

The present study demonstrates that in primary cultures of rat hepatocytes a moderate hypotonic stress resulted in a mild decrease of cytosolic G-actin, while F-actin was essentially unchanged, as demonstrated by two different methods. Simultaneously, the amount of actin mRNA was specifically increased. The results strongly support the hypothesis that in cultured hepatocytes the actin level is under autoregulatory control (14). This is in line with a previous study, which demonstrated an increase of actin mRNA after exposure of cultured hepatocytes to hypotonic or hypertonic medium, respectively (15). However, this study did not present data on the level of filamentous F-actin. The present results suggest that the autoregulation of actin synthesis is due to a specific modulation by the level of monomeric G-actin rather than by the level of filamentous F-actin. The lack of an alteration of F-actin levels during cytoskeletal rearrangement by osmotic stress might be explained by interaction with actin binding proteins or by formation of small actin oligomers, which might not be detected as filamentous actin (25). Moreover, the $\mathrm{C} 2$ toxin dependent inhibition of the osmotic decrease of G-actin and increase of actin mRNA argues against a direct osmotic effect on actin synthesis.

On the other hand, treatment of hepatocytes with phalloidin led to much stronger decrease of G-actin, which was not further enhanced by the simultaneous presence of hypotonic medium. This might be due to the extensive disturbance of the actin cytoskeleton observed in the presence of phalloidin. Nevertheless, this fourfold stronger decrease of G-actin did not effect a higher increase of actin mRNA within $2 \mathrm{~h}$ than osmotic stress did. Thus, it can be concluded that a moderate and essentially physiological decrease of G-actin by about $20 \%$, as observed during hypotonic stress, results in a maximal rate of increase of actin mRNA. Higher levels of actin mRNA observed during prolonged treatment 


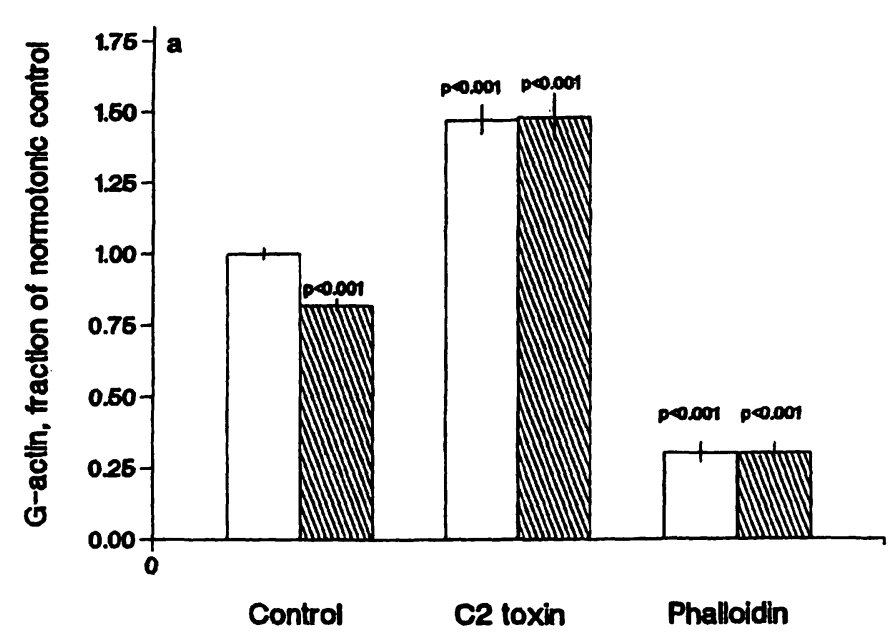

Fig. 3 Influence of $\mathrm{C} 2$ toxin and of phalloidin on the osmotic effect on G-actin (a) and actin mRNA (b) in rat hepatocytes. G-actin (a) and actin mRNA (b) was determined as described in figure 1 after 120 min of incubation with normotonic ( $\square$ ) or hypotonic $(\mathbb{\$})$ medium in the presence of phalloidin or $\mathrm{C} 2$ toxin. Means

with phalloidin (14) are apparently due to the longer lasting decrease of G-actin rather than to the stronger extent of the decrease. For that reason moderate physiological changes of the G-actin level or of the G-/F-actin equilibrium, as observed after osmotic stress or after exposure to hormones (26) are apparently sufficient for an effective regulation of actin synthesis.

The autoregulatory increase of actin mRNA in the presence of phalloidin is due to a specific transcriptional regulation, as recently demonstrated by nuclear run-on transcription studies (27). This might be true also for the autoregulation of actin synthesis observed during moderate alterations of the G-actin level by osmotic stress.

In spite of the cellular rearrangement during hypotonic stress, integrity of hepatocytes was not impaired by hypotonic medium, as indicated by lack of enzyme release

\section{References}

1. Korn ED. Actin polymerization and its regulation by proteins from nonmuscle cells. Physiol Rev 1982; 62:672 -737. .

2. Pollard TD, Cooper JA. Actin and actin-binding proteins. A critical evaluation of mechanisms and functions. Annu Rev Biochem 1986; 55:987-1035.

3. Cooper JA. The role of actin polymerization in cell motility. Annu Rev Physiol 1991; 53:585-605.

4. Tannenbaum J, Brett JG. Evidence for regulation of actin synthesis in cytochalasin D-treated HEp-2 cells. Exp Cell Res $1085 ; 160: 435-48$.

5. Leavitt J, Ng SY, Aebi U, Varma M, Latter G, Burbeck S, et al. Expression of transfected mutant beta-actin genes: alterations of cell morphology and evidence for autoregulation in actin pools. Mol Cell Biol 1987; 7:2457-66.

6. Bershadsky AD, Vasiliev JM. Cytoskeleton. New York, London: Plenum Press, 1988.

7. Serpinskaya A'S, Denisenko ON, Gelfand VI, Bershadsky AD. Stimulation of actin synthesis in phalloidin-treated cells. Evidence for autoregulatory control. FEBS Lett 1990; 277:11-4.

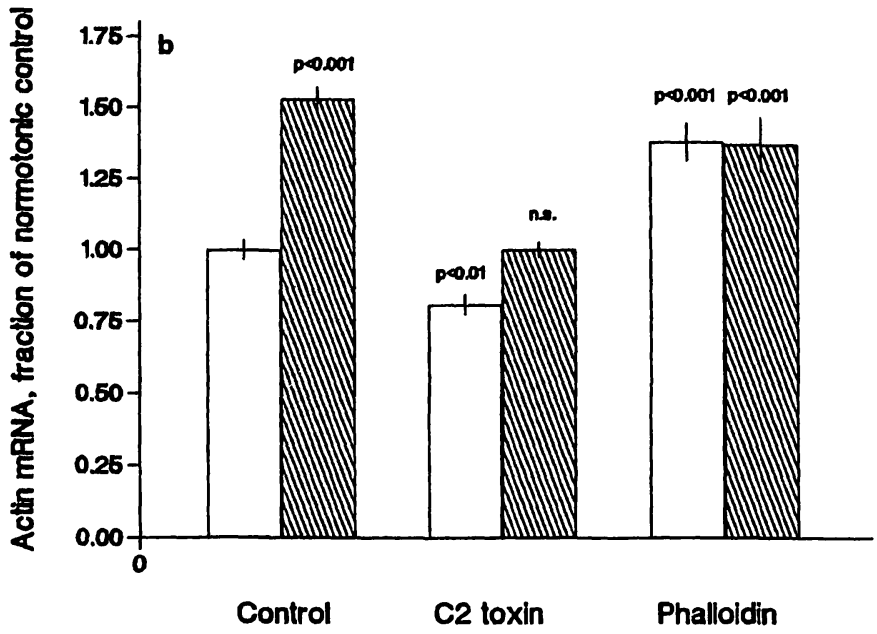

\pm S.E.M. of 7 separate determinations, compared to normotonic controls are given. The $P$ values were obtained by Student's t-test for unpaired data in comparison with control cells under normotonic conditions without toxins. n. s., not significant.

into the culture medium. Exclusively, when $\mathrm{C} 2$ toxin or phalloidin were added to hypotonic medium, the activities of alanine aminotransferase and aspartate aminotransferase in the culture medium were slightly increased. Possibly, the arrest of the cytosolic G-actin by $\mathrm{C} 2$ toxin or of the cytoskeletal F-actin by phalloidin hinders the cells to react to osmotic stress by swelling. Permeabilization of membranes may occur, since interactions between actin and liver cell membranes exist (28). Thus, hepatocyte culture in the presence of moderate hypoosmolarity can be regarded as a physiological model to study autoregulation of actin synthesis.

\section{Acknowledgements}

The skilful technical assistance of Monika Philipp is gratefully acknowledged. The study was supported by the Deutsche Forschungsgemeinschaft (Sonderforschungsbereich 249).
8. Lloyd C, Schevzov G, Gunning P. Transfection of nonmuscle beta- and gamma-actin genes into myoblasts elicits different feedback regulatory responses from endogenous actin genes. $J$ Cell Biol 1992; 117:787-97.

9. Cooper JA. Effects of cytochalasin and phalloidin on actin. J Cell Biol 1987; 105:1473-8.

10. Aktories K, Bärmann M, Ohishi I, Tsuyama S, Jakobs KH, Habermann E. Botulinum $\mathrm{C} 2$ toxin ADP-ribosylates actin. Nature 1986; 322:390-2.

11. Reuner KH, Presek P, Boschek CB, Aktories K. Botulinum C2 toxin ADP-ribosylates actin and disorganizes the microfilament network in intact cells. Eur J Cell Biol 1987; 43:134-40.

12. Wegner A, Aktories K. ADP-ribosylated actin caps the barbed ends of actin filaments. J Biol Chem 1988; 263:13739-42.

13. Aktories K, Reuner KH, Presek P, Bärmann M. Botulinum C2 toxin treatment increases the G-actin pool in intact chicken cells: a model for the cytopathic action of actin-ADP-ribosylating toxins. Toxicon 1989; 27:989-93. 
14. Reuner KH, Schlegel K, Just I, Aktories K, Katz N. Autoregulatory control of actin synthesis, in cultured rat hepatocytes. FEBS Lett 1991; 286:100-4.

15. Theodoropoulos PA, Stournaras C, Stoll B, Markogiannakis E, Lang F, Gravanis A, Häussinger D. Hepatocyte swelling leads to rapid decrease of the G-/total actin ratio and increases actin mRNA levels. FEBS Lett 1992; 311:241-5.

16. Giffhorn-Katz S, Katz NR. Carbohydrate-dependent induction of fatty acid synthase in primary cultures of rat hepatocytes. Eur J Biochem 1986; 159:513-8.

17. Ohishi I, Iwasaki M, Sakaguchi G. Purification and characterization of two components of botulinum C2 toxin. Infect Immun 1980; 30:668-73.

18. Blikstad IF, Markey F, Carlsson L, Persson T, Lindberg U. Selective assay of monomeric and filamentous actin in cell extracts, using inhibition of deoxyribonuclease I. Cell 1978; 15:935-43.

19. Wysolmerski RB, Lagunoff $D$. Inhibition of endothelial cell retraction by ATP depletion. Am J Pathol 1988; 132:28-37.

20. Suttorp N, Polley M, Seybold J, Schnittler H, Seeger W, Grimminger F, Aktories K. Adenosine diphosphate-ribosylation of $\mathrm{G}$-actin by botulinum $\mathrm{C} 2$ toxin increases endothelial permeability in vitro. J Clin Invest $1991 ; 87: 1575-84$.

21. Bradford $M$. A rapid and sensitive method for the quantitation of microgram quantities of protein utilizing the principle of protein-dye binding. Anal Biochem 1976; 72:248-54.

22. Phillips DR, Jennings LK, Edwards HH. Identification of membrane proteins mediating the interaction of human platelets. J Cell Biol 1980; 86:77-86.
23. Chomczynski P, Sacchi N. Single-step method of RNA isolation by acid guanidinium thiocyanate-phenol-chloroform extraction. Anal Biochem 1987; 162:156-9.

24. German Society for Clinical Chemistry. Standardization of methods for the estimation of enzyme activities in biological fluids. Z Klin Chem Klin Biochem 1972; 10:182-92.

25. Bremer A, Millong R, Sütterlin R, Engel A, Pollard TD, Aebi $U$. The structural basis for the intrinsic disorder of the actin filament: the "lateral slipping" model. J Cell Biol 1991; 115:689-703.

26. Rao KM, Betschart JM, Virii MA. Hormone-induced actin polymerization in rat hepatoma cells and human leucocytes. Biochem J 1985; 230:709-14.

27. Reuner $\mathrm{KH}$, Wiederhold $\mathrm{M}$, Dunker $\mathrm{P}$, Just I, Bohle RM, Kröger M, Katz N. Autoregulation of actin synthesis in hepatocytes by transcriptional and posttranscriptional mechanisms. Eur J Biochem 1995; 230:32-7.

28. Tranter MP, Sugrue SP, Schwartz MA. Binding of actin to liver cell membranes: the state of membrane-bound actin. J Cell Biol 1991; 112:891-901.

Dr. K. H. Reuner and Prof. Dr. N. Katz Institut für Klinische Chemie und Pathobiochemie der Universität Giessen Gaffkystraße 11 D-35392 Giessen Germany 